\title{
Metastatic renal cell carcinoma patients of T4 stage who are in status of N1 stage or older than 76 years cannot benefit from cytoreductive nephrectomy
}

\author{
Zhao Zhang, Hongliang Wu, Tong Yang, Yaohai Wu, Nengwang Yu*iD and Zhonghua Xu
}

\begin{abstract}
Background: We aimed to identify which part of the patients with metastatic renal cell carcinoma (mRCC) is not suitable for cytoreductive nephrectomy (CN).

Methods: The data of mRCC patients was acquired from the Surveillance, Epidemiology, and End Results (SEER) database. Multivariate cox regression analysis and nomogram were performed for selecting factors independently associated with survival. Propensity score matching (PSM) was applied to reduce potential bias when comparing survival of mRCC patients treated by CN or non-surgery (NS). The survival analysis of subgroups was estimated by the Kaplan-Meier method and compared by log-rank testing. The summary of subgroup analysis was showed by forest plots.
\end{abstract}

Results: The records of 21,411 patients with mRCC were obtained from the SEER database. After screening, a total of 6532 patients were included for further analysis, of which 6043 underwent CN and 489 underwent NS. Age, T stage, $\mathrm{N}$ stage and tumor size were involved in subgroup analysis by PSM according to the result of multivariate cox regression analysis and clinical experience. Survival benefit was not found in T4 stage patients. Further analysis showed that T4\&N1 and T4\&age $\geq 76$ yr subgroups could not obtain survival benefit from CN.

Conclusion: CN should not be performed in T4 stage mRCC patients who were in status of N1 stage or older than 76 years, because surgery cannot take significant survival benefit for them.

Keywords: Renal cell carcinoma, Cytoreductive nephrectomy, Survival, SEER

\section{Background}

Renal cell carcinoma (RCC) accounts for approximately $3 \%$ of adult malignancies and 90-95\% of kidney neoplasms, $25-30 \%$ of patients present with metastatic disease at time of diagnosis. Metastatic RCC (mRCC) is one of the most treatment-resistant malignancies and its prognosis is generally poor and median survival after diagnosis is very short [1]. Cytoreductive nephrectomy

\footnotetext{
* Correspondence: qiluyunengwang@hotmail.com

Department of Urology, Qilu Hospital of Shandong University, Wenhuaxi Road 107\#, Jinan 250012, P.R. China
}

(CN) was established as a therapy which can improve antitumor immune system response during the era of immunotherapy, given the results of two randomized trials demonstrating an overall survival (OS) advantage of 5.8 months in a combined analysis study [2]. However, targeted therapies (TTs) emerged and demonstrated superiority to immunotherapy, becoming the standard of systemic therapy (ST) in mRCC. The role of $\mathrm{CN}$ in $\mathrm{mRCC}$ has been questioned because some patients are unable to receive $\mathrm{TT}$ after $\mathrm{CN}$ due to disease progression or perioperative complications. CARMENA, a

(c) The Author(s). 2020 Open Access This article is licensed under a Creative Commons Attribution 4.0 International License, which permits use, sharing, adaptation, distribution and reproduction in any medium or format, as long as you give appropriate credit to the original author(s) and the source, provide a link to the Creative Commons licence, and indicate if changes were made. The images or other third party material in this article are included in the article's Creative Commons licence, unless indicated otherwise in a credit line to the material. If material is not included in the article's Creative Commons licence and your intended use is not permitted by statutory regulation or exceeds the permitted use, you will need to obtain permission directly from the copyright holder. To view a copy of this licence, visit http://creativecommons.org/licenses/by/4.0/ The Creative Commons Public Domain Dedication waiver (http://creativecommons.org/publicdomain/zero/1.0/) applies to the data made available in this article, unless otherwise stated in a credit line to the data. 
randomized controlled trial, suggested treatment with targeted kinase inhibitors (TKIs) alone was not inferior to upfront $\mathrm{CN}$ combined with TKIs in certain mRCC patients [3]. For now, it is not well understood if $\mathrm{CN}$ should remain a part of the standard treatment protocol.

A research demonstrated that large benefit exists in both overall survival (OS) and progression- free survival (PFS) in patients receiving a CN compared with those without, even after adjusting for imbalances [4]. The latest guidelines suggest that only patients who in the state of International Metastatic RCC Database Consortium (IMDC) favorable and intermediate risk need CN [5]. In order to better understand the role of $\mathrm{CN}$ in $\mathrm{mRCC}$, we retrospectively analyzed the records of $\mathrm{mRCC}$ in the SEER (Surveillance, Epidemiology and End Results) database and compared the differences in survival among different subgroups treated with $\mathrm{CN}$ or non-surgical (NS) after balancing other variables that affected survival.

\section{Methods}

\section{Data source and patient selection}

The SEER database is a cancer-based registry sponsored by the NCI (National Cancer Institute) which incorporates high quality data derived from 18 cancer registries and covers approximately $27.8 \%$ of the U.S. population (based on the 2010 census) [6]. We identified patients diagnosed with renal tumor (ICD-0-3 primary site code C64.9) and M1(Derived AJCC M, 6th ed) stage from 2004 to 2015 as mRCC cohort. Patients without exact T stage, $\mathrm{N}$ stage, tumor size or survival time were excluded. Patients with code 0 of RX Summ--Surg Prim Site were considered NS group while code 40 and 50 were considered $\mathrm{CN}$ group. Only patients who were recommended surgery were involved our research.

\section{Variables}

Variables were obtained using the SEER registries. These variables included sex, race, age at diagnosis, derived AJCC T, 6th ed. (2004-2015), derived AJCC N, 6th ed. (2004-2015), derived AJCC M, 6th ed. (2004-2015), RX Summ-Surg Prim Site (1998+), CS tumor size (2004+), SEER cause-specific death classification, Survival months, vital status recode (study cutoff used), Reason no cancer-directed surgery.

\section{The process of propensity score matching (PSM)}

The main process of PSM was divided into three steps. At first, continuous variables such as age at diagnosis and tumor size were transformed into categorical variables to identify the best cut-off point based on the lowest $P$ values and the maximum chi-square of log-rank tests by using X-Tile 3.6.1 software (Yale University) [7]. Secondly, by multivariate cox regression analysis and nomogram plot, variables which can significantly influence cancer specific survival (CSS) of patients were picked out. Thirdly, PSM was performed to reduce potential confounding effects and treatment selection bias by balancing the variables which were selected when comparing CSS between $\mathrm{CN}$ and NS in different subgroups. PSM was conducted using the package of "MatchIt" in $\mathrm{R}$ version 3.5.3. A 1:2(NS:CN) nearestneighbor matching with a caliper distance of 0.2 was used.

\section{Statistical analysis}

We compared the cancer specific survival (CSS) among subgroups of mRCC patients treated by $\mathrm{CN}$ or NS, using PSM. Then we verified the results by comparing overall survival (OS) between patients treated by $\mathrm{CN}$ or NS. Continuous variables were compared with the Student's t-test. Unordered categorical variables were compared by chi-square tests. Ordered categorical variables were compared by Goodman and Kruskal's gamma. If the expected frequency was less than five, Fisher's exact tests were used. The Mann-Whitney $U$ test was applied to compare variables that did have an unnormal distribution. Cumulative survival was estimated by the KaplanMeier method and compared by log-rank tests. Statistical analysis was achieved by packages of $\mathrm{R}$ software (3.5.3), including MatchIt, tableone and survival. All tests were two sided; $p$-value $<0.05$ was considered significant.

\section{Results \\ Data}

We identified 21,411 mRCC patients with ICD-0-3 primary site code C64.9 and M1 stage. Among them, 8478 patients were recommended for surgery. Only 7515 patients meted the code of RX Summ--Surg Prim Site 0 (NS), $40(\mathrm{CN})$ or $50(\mathrm{CN})$. Then 449 pitients with TX and 428 patients with NX were excluded. After that, 106 cases with unknown, abnormal or inaccurate tumor size were excluded (CS tumor size code 0, 600, 700, 800, 900,920,930,950,980,989,990-999). Finally, a total of 6532 cases which met our inclusion criteria were retrieved, including 6043 that underwent $\mathrm{CN}$ and 489 cases that received NS. Table 1 showed patient demographics and clinical characteristics of these patients.

\section{Multivariate cox regression analysis and nomogram plot}

Through X-Tile, we figured out the best cut-off points for age at diagnosis and tumor size as 76-years-old (maximum chi-square 31.3, Miller-Seigmund $P<0.0001$ ) and $82 \mathrm{~mm}$ (maximum chi-square 45.5, Miller-Seigmund $\mathrm{P}<0.0001$ ), respectively. According to the latest guideline and for the convenience of analysis, we unified N2 and N1 in derived AJCC T, 6th ed. (2004-2015) as N1. Nomogram plot in Fig. 1 showed the weight of every 
Table 1 Patient demographics and clinical characteristics for patients of $\mathrm{CN}$ and NS group

\begin{tabular}{|c|c|c|c|}
\hline & $\mathrm{CN}(\boldsymbol{N}=6043)$ & NS $(\boldsymbol{N}=489)$ & Overall $(\boldsymbol{N}=6532)$ \\
\hline \multicolumn{4}{|l|}{ Age (years) } \\
\hline Mean (SD) & $60.7(11.5)$ & $69.5(12.9)$ & $61.3(11.8)$ \\
\hline Median [Min, Max] & $61.0[8.00,95.0]$ & $71.0[32.0,95.0]$ & $61.0[8.00,95.0]$ \\
\hline \multicolumn{4}{|l|}{ Sex } \\
\hline Female & 1798 (29.8\%) & $193(39.5 \%)$ & 1991 (30.5\%) \\
\hline Male & $4245(70.2 \%)$ & $296(60.5 \%)$ & 4541 (69.5\%) \\
\hline \multicolumn{4}{|l|}{ Race } \\
\hline Black & 478 (7.9\%) & 71 (14.5\%) & 549 (8.4\%) \\
\hline Other & 439 (7.3\%) & $42(8.6 \%)$ & $481(7.4 \%)$ \\
\hline White & $5126(84.8 \%)$ & 376 (76.9\%) & $5502(84.2 \%)$ \\
\hline \multicolumn{4}{|l|}{ T stage } \\
\hline $\mathrm{T} 1$ & 749 (12.4\%) & $180(36.8 \%)$ & $929(14.2 \%)$ \\
\hline $\mathrm{T} 2$ & 886 (14.7\%) & $121(24.7 \%)$ & $1007(15.4 \%)$ \\
\hline T3 & $3926(65.0 \%)$ & $134(27.4 \%)$ & $4060(62.2 \%)$ \\
\hline $\mathrm{T} 4$ & $482(8.0 \%)$ & $54(11.0 \%)$ & $536(8.2 \%)$ \\
\hline \multicolumn{4}{|l|}{$\mathrm{N}$ stage } \\
\hline NO & $4243(70.2 \%)$ & $324(66.3 \%)$ & 4567 (69.9\%) \\
\hline N1 & $1800(29.8 \%)$ & $165(33.7 \%)$ & 1965 (30.1\%) \\
\hline \multicolumn{4}{|l|}{ Histologic type } \\
\hline Chromophobe & $74(1.2 \%)$ & $2(0.4 \%)$ & $76(1.2 \%)$ \\
\hline Clear Cell & 4582 (75.8\%) & $401(82.0 \%)$ & $4983(76.3 \%)$ \\
\hline Papillary & 314 (5.2\%) & $14(2.9 \%)$ & $328(5.0 \%)$ \\
\hline other & $1073(17.8 \%)$ & $72(14.7 \%)$ & 1145 (17.5\%) \\
\hline \multicolumn{4}{|c|}{ Survival time (months) } \\
\hline Mean (SD) & $26.6(28.6)$ & $11.8(18.9)$ & $25.5(28.3)$ \\
\hline Median [Min, Max] & $17.0[0,155]$ & $5.00[0,130]$ & $15.0[0,155]$ \\
\hline
\end{tabular}

variable in the result of multivariate cox analysis. It demonstrated that sex $(P=0.01)$, age $(P=0)$, race $(P=0.02)$, T stage $(P=0), \mathrm{N}$ stage $(P=0)$ and tumor size $(p=0)$ were independent risk factors for CSS of total mRCC patients. Therefore, in the next subgroup analysis, the PSM was performed for balancing sex, race, age, tumor size, $\mathrm{T}$ stage, and $\mathrm{N}$ stage in $\mathrm{CN}$ - or NS-treated mRCC patients.

\section{Subgroup analysis}

First, we compared the CSS of mRCC patients treated by $\mathrm{CN}$ or NS for subgrouping under each variable (age, sex, race, $\mathrm{T}$ stage, $\mathrm{N}$ stage, and tumor size). Other variables were balanced by PSM to reduce potential confounding effects and treatment selection bias when comparing subgroup of one variable. Survival benefits were found in patients treated by $\mathrm{CN}$ in almost all subgroups except T4 subgroup. Although there were 8 months benefit of median CSS time in T4 subgroup patients, the HR (95\% CI) was 0.801 to 1.816 , crossing 1 (Fig. 2). This was consistent with the result of KM survival analysis, showing that in T4 subgroup the CSS between $\mathrm{CN}$ (95 cases) and NS (50 cases) had no statistical significance (Fig. 4a, $p=$ 0.29 ).

In order to further explore which factors may prevent patients of T4 subgroup from benefiting from $\mathrm{CN}$, we matched T4 stage with age, $\mathrm{N}$ stage and tumor size respectively to group them in more detail (Fig. 3). Table 2 showed the result of PSM in T4 stage patients. The result showed that the patients in T4\&N0 subgroup and T4\&age $<76 \mathrm{yr}$ subgroup could still obtain CSS benefit from $\mathrm{CN}$ while $\mathrm{T} 4 \& \mathrm{~N} 1$ subgroup and $\mathrm{T} 4 \&$ age $\geq 76 \mathrm{yr}$ could not, meaning $\mathrm{N} 1$ and age $\geq 76 \mathrm{yr}$ were high risk factors which influenced prognosis (Fig. 4b, c). In addition, there was no significant difference in CSS between $\mathrm{CN}$ - and NS-treated mRCC patients, whether in T4\&tumor-size $<82 \mathrm{~mm}$ subgroup or T4\&tumor-size $\geq 82$ $\mathrm{mm}$ subgroup. It suggested that although multivariate COX results show that tumor size was an independent prognostic factor, tumor size had little effect on CSS of T4 stage mRCC. At last, we compared OS between 


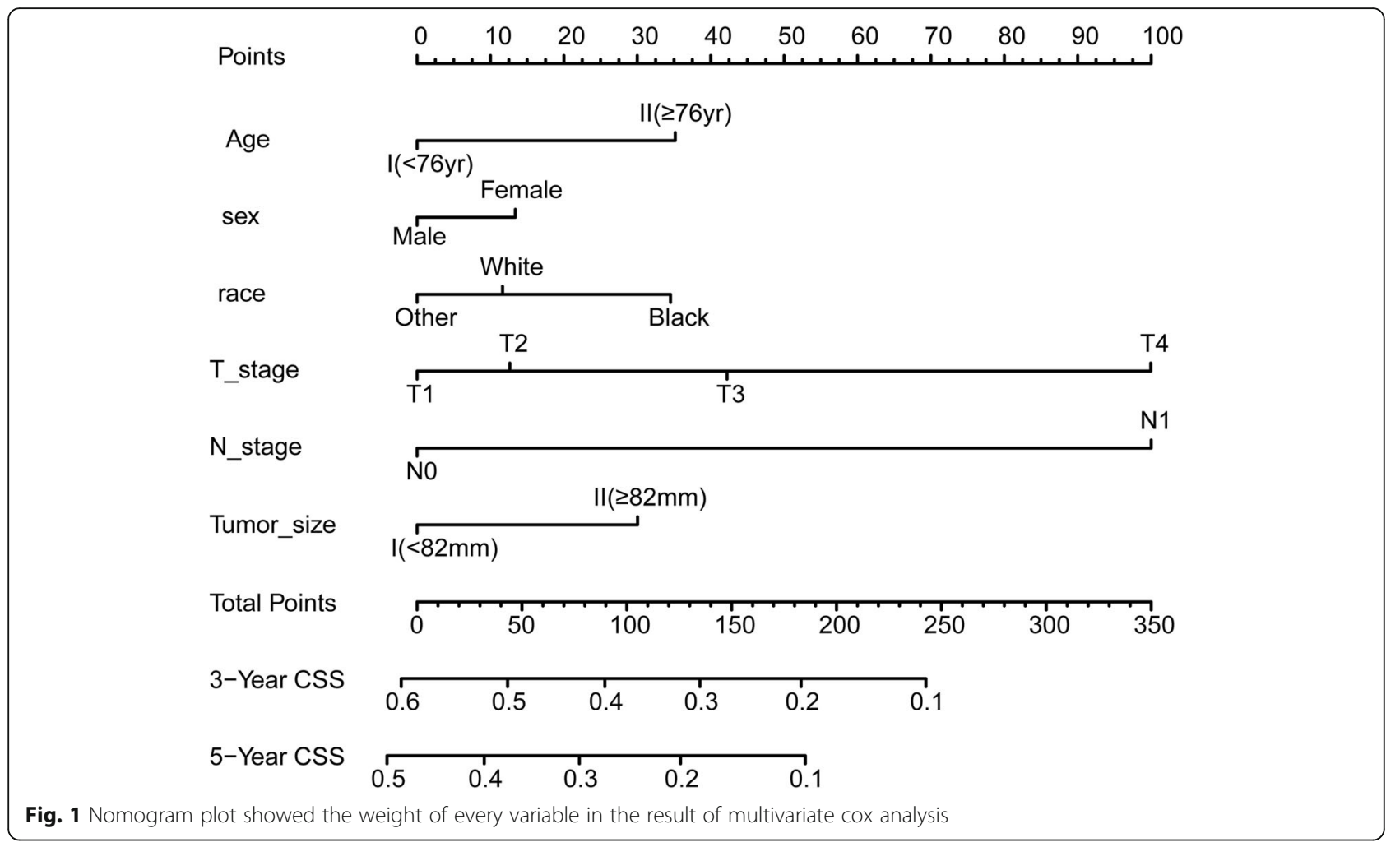

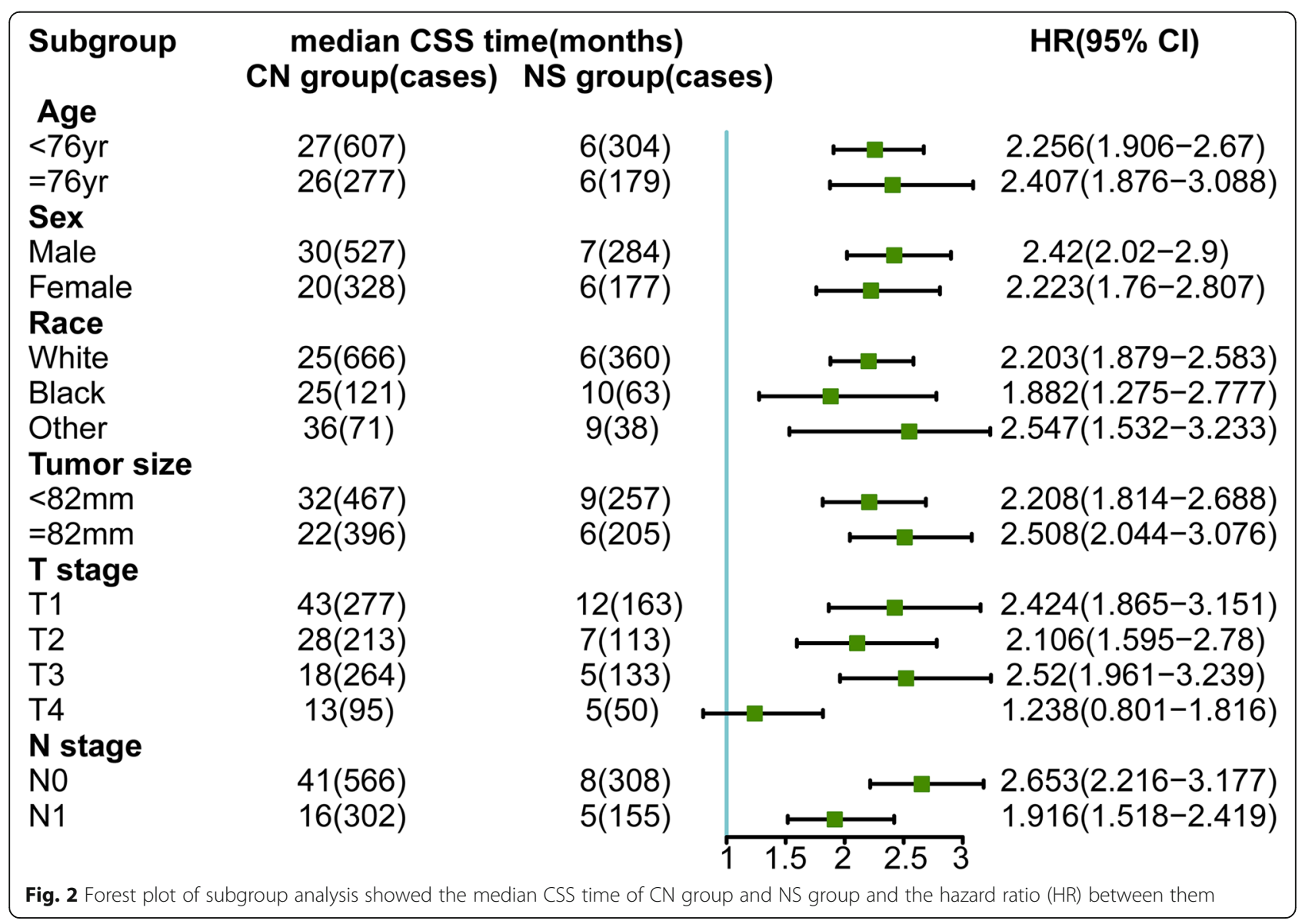




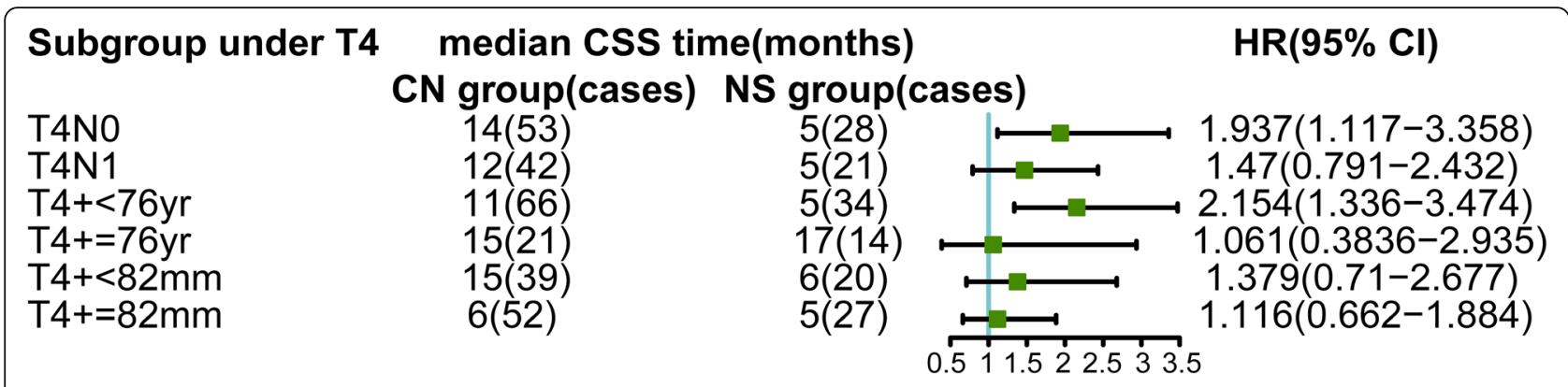

Fig. 3 Forest plot of further subgroup analysis under T4 stage

patients who received $\mathrm{CN}$ or $\mathrm{NS}$ in $\mathrm{T} 4, \mathrm{~T} 4 \& \mathrm{~N} 1$ and T4\&age $\geq 76$ yr subgroups. The result showed the patients of these subgroups also cannot acquire OS benefit from CN (Fig. 4d, e, f).

\section{Discussion}

Various treatments have been proposed for mRCC. The use of $\mathrm{CN}$ in the immunotherapy era was based on two randomized trials conducted by the European Organization for Research and Treatment of Cancer and by the Southwest Oncology Group $[8,9]$. In the TT era, CARMENA [3] and SURTIME [10] have greatly weakened the role of $\mathrm{CN}$ in the initial treatment of $\mathrm{mRCC}$. CARMENA, as a randomized trial, represents the highest level of evidence to date on the role of $\mathrm{CN}$. However, this trial may be underpowered to detect a true survival benefit because it was enriched with poor-risk patients who cannot obtain a benefit from $\mathrm{CN}$ and had a relatively small sample size and an accrual period of 10 years. Besides, it remains unknown whether patients traditionally thought to benefit from $\mathrm{CN}$, such as those with a limited metastatic burden, were actually included in CARMENA. Researches had shown that patients with mRCC displayed significant variability in oncologic outcomes after $\mathrm{CN}$ and systemic therapy [11, 12]. Bhindi et al. reported $\mathrm{CN}$ may bring survival benefit to patients with limited metastatic burden, well-selected patients, and patients with favorable response after initial systemic therapy or for symptom's palliation [13]. Larcher et al. found that $\mathrm{CN}$ could not offer survival benefit for poor or intermediate risk patients who were eligible for systemic therapy [14]. While these analyses differ in their findings on $\mathrm{CN}$, they do not fully deny $\mathrm{CN}$. They believe that the premise that $\mathrm{CN}$ can benefit patients is to strictly limit the indications of $\mathrm{CN}$. Thus, $\mathrm{CN}$ likely still has a vital role in the treatment of mRCC patients. It is of great importance to judge which part of patients are not suitable for $\mathrm{CN}$, which can avoid surgery in patients who are unlikely to derive clinical benefit from a surgical intervention.

In the present study, we compared cancer-specific survival among different subgroups of mRCC patients treated with $\mathrm{CN}$ or NS, after balancing other variables impacting survival. A special and important inclusion

Table 2 The results of propensity score matching (PSM) in subgroups. (only show T4, T4 + Agell and T4 + N1 subgroups)

\begin{tabular}{|c|c|c|c|c|c|c|c|c|}
\hline \multirow[b]{2}{*}{ T4 } & \multicolumn{2}{|l|}{ Variables } & \multicolumn{2}{|l|}{$\mathrm{CN}$} & \multicolumn{2}{|l|}{ NS } & \multicolumn{2}{|c|}{ Significant } \\
\hline & & & No. & $\%$ & No & $\%$ & $P$ & Method \\
\hline & N & 0 & 53 & 55.8 & 29 & 58 & 0.937 & chi-square \\
\hline & & 1 & 42 & 44.2 & 21 & 42 & & \\
\hline & & & Mean & SD & Mean & SD & $P$ & Method \\
\hline & Age (years) & & 65.2 & 11.8 & 65.9 & 13.6 & 0.72 & t-test \\
\hline & Tumor Size (mm) & & 91.2 & 42.7 & 88.9 & 42 & 0.754 & t-test \\
\hline \multirow[t]{5}{*}{ T4 + Agell } & & & No. & $\%$ & No & $\%$ & $P$ & Method \\
\hline & $\mathrm{N}$ & 0 & 17 & 81 & 10 & 71.4 & 0.805 & chi-square \\
\hline & & 1 & 4 & 19 & 4 & 28.6 & & \\
\hline & & & Mean & SD & Mean & $\mathrm{SD}$ & $P$ & Method \\
\hline & Tumor Size (mm) & & 83.8 & 22.7 & 82.1 & 28.8 & 0.849 & t-test \\
\hline \multirow[t]{3}{*}{$\mathrm{T} 4+\mathrm{N} 1$} & & & Mean & SD & Mean & SD & $P$ & Method \\
\hline & Age (years) & & 62.9 & 10.9 & 61.8 & 13.2 & 0.721 & t-test \\
\hline & Tumor Size (mm) & & 86.4 & 37.5 & 89.8 & 39.8 & 0.742 & t-test \\
\hline
\end{tabular}




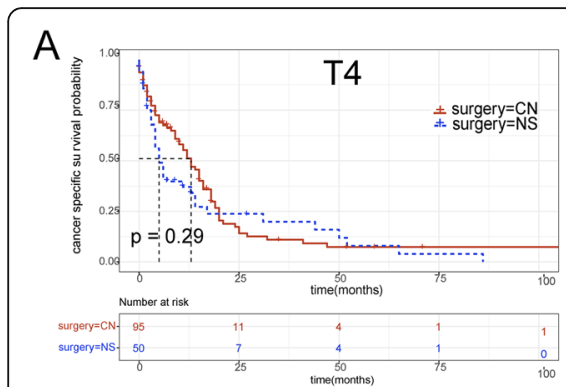

D

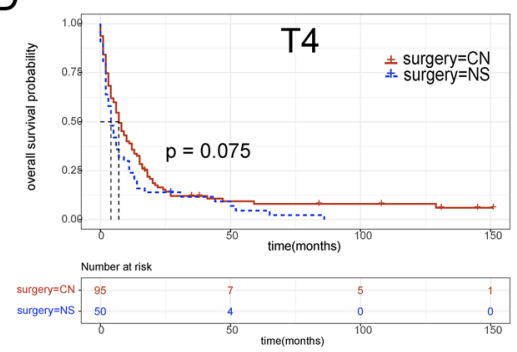

B

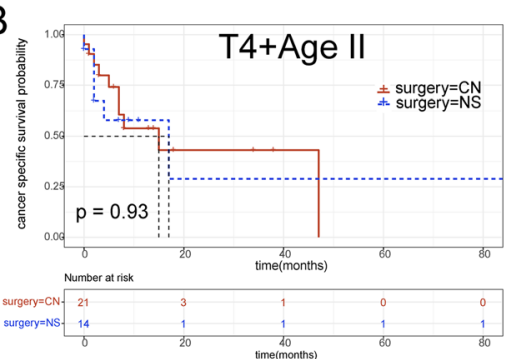

E

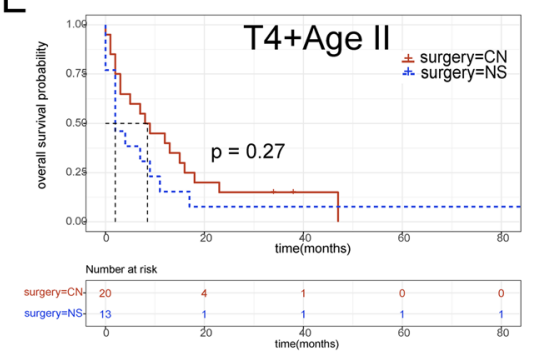

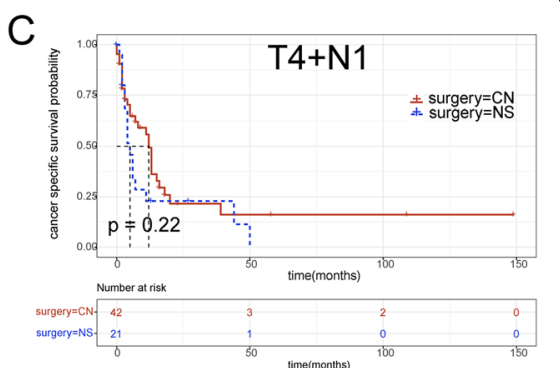

$\mathrm{F}$

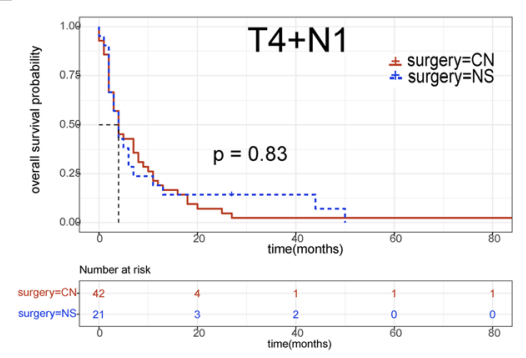

Fig. 4 Kaplan-Meier survival curve (OS and CSS) between CN group and NS group in subgroup analysis. (only show T4, T4 + Agell and T4 + N1 subgroups)

criterion is that all patients must be recommended for surgery by doctors. We found that the CSS of CN patients was better than that of NS patients in almost all subgroups under each variable, which confirmed the value of $\mathrm{CN}$ in clinical treatment. Only the patients of T4 subgroup cannot obtain cancer specific survival benefit from $\mathrm{CN}$. Further analysis suggested that age and $\mathrm{N}$ stage were two risk factors under T4 stage. T4 stage Patients who were in status of N1 stage or older than 76 years of age cannot benefit from CN. In terms of overall survival, patients in these subgroups were still unable to benefit from $\mathrm{CN}$. Therefore, $\mathrm{CN}$ is not suitable for this part of patients. When faced with these patients, we should carefully consider how to choose the most appropriate treatment.

To help oncologists and surgeons assure the best indication for $\mathrm{CN}$ and avoid unnecessary surgery, the method of preoperative identification is urgently needed. Previous study has shown that patients with high or intermediate scores can acquire survival benefit from $\mathrm{CN}$ under the MSKCC criteria. In addition, according to the ECOG score standard, only patients with a score of 0 or 1 can benefit from $\mathrm{CN}$ [15]. Culp et al. previously devised a risk group-based model using seven clinical variables available prior to $\mathrm{CN}$. Patients who had four or more adverse parameters did not appear to benefit from surgery, because their overall survival was similar to the cohort of patients with mRCC who received medical therapy alone [16]. To date, no validated standard can be used to screen mRCC patients who are suitable for $\mathrm{CN}$. To our knowledge, the present study included the largest samples of mRCC patients and focused on subgroup analysis by clinical information for the first time. It is very important that we limit the inclusion to only the patients recommended surgery by doctor can be involved and this This can greatly narrow the selection bias. The results of this study may contribute to future clinical decisions. More randomized controlled trials comparing $\mathrm{CN}$ and NS should be conducted and new effective methods for selection of patients should be developed in the future.

The current study exists several limitations. First, SEER data may be limited by unrecorded variables, underreported and incomplete data, variations in data coding and reporting, and migration of patients in and out of the SEER registry area. Second, there was no available detailed information of systemic therapy such as targeted therapy, chemotherapy, and immunotherapy for the cohort of mRCC patients. We did not know whether systemic therapies between the $\mathrm{CN}$ and NS groups were balanced. Third, there was no unified criteria for patients who were recommended $\mathrm{CN}$. This may lead to the instability of the included data and affect the final analysis results. Fourth, the selection bias between $\mathrm{CN}$ and NS groups could not be completely eliminated by PSM because there was a wide gap in the sample amount between the two groups and the clinical information included in PSM was limited. Fifth, the AJCC TNM stage of our data is 6th edition while several modifications in $\mathrm{T}$ and $\mathrm{N}$ stages have been made in the 8th edition. When applying the results of this study, the differences between different versions should be taken into account. Sixth, the small sample size of some subgroup 
after PSM may lead to inaccuracy and randomness of the results.

\section{Conclusion}

$\mathrm{CN}$ should be performed in all patients who under $\mathrm{T} 1$, T2 or T3 stage because they can obtain survival benefit from surgery. In T4 stage, $\mathrm{N} 1$ and age $\geq 76 \mathrm{yr}$ are two high risk factors. Patients who are in T4\&N1 subgroup or T4\&age $\geq 76$ yr subgroup cannot benefit in CSS from $\mathrm{CN}$ significantly. In the face of $\mathrm{T} 4$ stage mRCC patients, we should choose the treatment therapy carefully and $\mathrm{CN}$ is not recommended as the first-line strategy.

\section{Abbreviations}

mRCC: Metastatic renal cell carcinoma; CN: Cytoreductive nephrectomy; NS: Non-surgery; PSM: Propensity score matching; CSS: Cancer specific survival; SEER: Surveillance, epidemiology and end results database

\section{Acknowledgements}

We thank the Surveillance, Epidemiology, and End Results (SEER) program for providing access to its research data file for free.

\section{Authors' contributions}

NWY and ZZ designed the study. ZZ wrote the article. HLW collected and analyzed the data. YHW and TY made the figures and tables. NWY and ZHX revised and edited the article. All authors read and approved the final manuscript.

\section{Funding}

This study was supported by the Focused Research and Development Program of Shandong Province (No.2017GSF18162), the Natural Science Foundation of Shandong Province (No. ZR2018MH024), and the Focused Research and Development Program of Shandong Province (No. 2017GSF18130). The funding bodies were not involved in the design of this study, in the collection, analysis, and interpretation of the data, or in writing of the manuscript.

\section{Availability of data and materials}

The datasets used and/or analyzed during this current study are available from the corresponding author on reasonable request.

\section{Ethics approval and consent to participate}

We obtained the permission to access the SEER database with the ID number 10616-Nov2018 via Internet access method. Ethical approval was waived by the local ethics committee, as SEER data is publicly available, deidentified.

\section{Consent for publication}

Not applicable.

\section{Competing interests}

The authors declare that they have no conflict of interest.

Received: 15 March 2020 Accepted: 26 August 2020

Published online: 03 September 2020

\section{References}

1. Gupta K, Miller JD, Li JZ, Russell MW, Charbonneau C. Epidemiologic and socioeconomic burden of metastatic renal cell carcinoma (mRCC): a literature review. Cancer Treat Rev. 2008;34(3):193-205.

2. Bhindi B, Habermann EB, Mason RJ, Costello BA, Pagliaro LC, Thompson RH, et al. Comparative survival following initial Cytoreductive nephrectomy versus initial targeted therapy for metastatic renal cell carcinoma. J Urol. 2018;200(3):528-34.

3. Mejean A, Ravaud A, Thezenas S, Colas S, Beauval JB, Bensalah K, et al. Sunitinib alone or after nephrectomy in metastatic renal-cell carcinoma. N Engl J Med. 2018;379(5):417-27.
4. Heng DY, Wells JC, Rini BI, Beuselinck B, Lee JL, Knox JJ, et al. Cytoreductive nephrectomy in patients with synchronous metastases from renal cell carcinoma: results from the international metastatic renal cell carcinoma database consortium. Eur Urol. 2014:66(4):704-10.

5. EAU Guidelines. Edn: presented at the EAU annual congress Barcelona; 2019. ISBN 978-94-92671-04-2.

6. Surveillance, Epidemiology, and End Results (SEER) Program (www.seer. cancer.gov) SEERStat Database Incidence - SEER 18 Regs Research Data + Hurricane Katrina Impacted Louisiana Cases, Nov 2018 Sub (1975-2016 varying).

7. Camp RL, Dolled-Filhart M, Rimm D. L: X-tile a new bio-informatics tool for biomarker assessment and outcome-based cut-point optimization. Clin Cancer Res. 2004;10(21):7252-9.

8. Mickisch GHJ, Garin A, van Poppel H, de Prijck L, Sylvester R. Radical nephrectomy plus interferon-alfa-based immunotherapy compared with interferon alfa alone in metastatic renal-cell carcinoma: a randomised trial. Lancet. 2001;358(9286):966-70.

9. Flanigan RC, Salmon SE, Blumenstein BA, et al. Nephrectomy followed by interferon alfa-2b compared with interferon alfa-2b alone for metastatic renal-cell cancer. N Engl J Med. 2002;345(23):1655-9.

10. Bex AMP, Jewett $M$, et al. Surgical safety of immediate versus deferred cytoreductive nephrectomy $(\mathrm{CN})$ in patients with synchronous metastatic renal cell carcinoma ( $\mathrm{mRCC}$ ) receiving sunitinib. Data from the EORTC randomized trial 30073 SURTIME. Eur Urol Suppl. 2018;17(2):e1-2.

11. Motzer RJ, Bukowski RM, Figlin RA, Hutson TE, Michaelson MD, Kim ST, et al. Prognostic nomogram for sunitinib in patients with metastatic renal cell carcinoma. Cancer. 2008;113(7):1552-8.

12. Choueiri TK, Rini B, Garcia JA, Baz RC, Abou-Jawde RM, Thakkar SG, et al. Prognostic factors associated with long-term survival in previously untreated metastatic renal cell carcinoma. Ann Oncol. 2007;18(2):249-55.

13. Bhindi B, Abel EJ, Albiges L, Bensalah K, Boorjian SA, Daneshmand S, et al. Systematic review of the role of Cytoreductive nephrectomy in the targeted therapy era and beyond: an individualized approach to metastatic renal cell carcinoma. Eur Urol. 2019;75(1):111-28.

14. Larcher A, Wallis CJD, Bex A, Blute ML, Ficarra V, Mejean A, et al. Individualised indications for Cytoreductive nephrectomy: which criteria define the optimal candidates? Eur Urol Oncol. 2019:2(4):365-78.

15. Mathieu R, Pignot G, Ingles A, Crepel M, Bigot P, Bernhard JC, et al. Nephrectomy improves overall survival in patients with metastatic renal cell carcinoma in cases of favorable MSKCC or ECOG prognostic features. Urol Oncol. 2015;33(8):339 e339.

16. Culp SH, Tannir NM, Abel EJ, Margulis V, Tamboli P, Matin SF, et al. Can we better select patients with metastatic renal cell carcinoma for cytoreductive nephrectomy? Cancer. 2010;116(14):3378-88.

\section{Publisher's Note}

Springer Nature remains neutral with regard to jurisdictional claims in published maps and institutional affiliations.

\section{Ready to submit your research? Choose BMC and benefit from:}

- fast, convenient online submission

- thorough peer review by experienced researchers in your field

- rapid publication on acceptance

- support for research data, including large and complex data types

- gold Open Access which fosters wider collaboration and increased citations

- maximum visibility for your research: over $100 \mathrm{M}$ website views per year

At BMC, research is always in progress.

Learn more biomedcentral.com/submissions 